\title{
1977 American Pediatric Society Presidential Address
}

\author{
MARGARET H. D. S.MITH \\ Oschner Clinic, New Orleans, Lotwisiana, USA
}

\begin{abstract}
Members of The American Pediatric Society, Future Members of The American Pediatric Society, Honored Guests: Let me first welcome to our midst the distinguished colleagues who have travelled from other countries to be with us this week. I shall start with Switzerland, out of personal bias, since 1 grew up there and consider it my alma mater.... We urge all of our visitors to participate fully in the program, to enter into the discussions, and to give us the benefit of their thinking and experience. We hope that they will consider themselves automatically invited to the social functions put on by the various pediatric groups, and by The American Pediatric Society to honor its new members. And we hope that they will enjoy this, the most charming of all American cities, which seems to fuse the best of Europe and the best of America.
\end{abstract}

This gavel, with which I have the great pleasure of opening the 87th Annual Meeting of The American Pediatric Society, has lain on my desk all year. Just as I believe in enjoying one's best china and silver every day of one's life, so I have savored the honor you conferred upon me in electing me your president. The gavel has been an inspiration, as I know it was to my predecessors and will be to my successors. Its origin is described in the volume entitled History of the American Pediatric Society, published in 1966 by Harold Faber and Rustin McIntosh, both former presidents of this Society, a volume which I have read and reread this year. The History states on page 228 that at the business meeting of the Society in 1949 "Helmholz of Rochester, Minnesota"-himself a former president of the Society- "presented to the Society a gavel carved from the wood of a thorn tree which had grown beside the house in Ontario where Osler was born. From this tree three gavels had been fashioned, of which one was given to The American Pediatric Society, a second to The Association of American Physicians and the third to The Interurban Clinical Club." Whose idea was it to cut down a thorn tree next to Osler's house? Who actually carved the gavels? Who selected the fortunate recipients? I telephoned Dr. Rustin McIntosh to find out, but he tells me that the rest of the story has, alas, been forgotten.

The early relationship of this Society to The Association of American Physicians and to William Osler is nevertheless brought out by the story even as it stands. The first organizing meeting of the Society was in 1886. Among the original members of The Association of American Physicians were six who also became original members of The American Pediatric Society, including William Osler himself, who became fourth president of our Society; Abraham Jacobi, its first president, and Frederick Forchheimer (who first described the enanthem of rubella!). All three in time became presidents of both societies.

The original purpose of this Society was stated as follows: "The Society has for its object the advancement of the Physiology, Pathology and Therapeutics of Infancy and Childhood." The programs of early annual meetings revolved entirely around clinical and simple epidemiologic observations, group discussions. reports of new procedures such as lumbar puncture in 1896.

While the scientific sessions were described by President John Lovett Morse as "always interesting and instructive," he added that "The most striking thing about the meetings of The Society has been, however, the spirit of good fellowship which always prevailed." The secretary for twenty-five years was the "genial, hustling, bustling Dr. Samuel S. Adams. No one but he could have persuaded The Baltimore and Ohio Railroad to take the Society in a private car from New York to Deer Park, Maryland, put us up in its hotel there and deliver us back in New York, all free of charge"-obviously the model of a very perfect secretary. And so we find added to the stated scientific purpose of the Society the warm feelings of friendship and mutual interest that characterize a club.

A landmark year for The American Pediatric Society was 1899. for the subject of the presidential address for that year was Methods of Instruction in Pediatrics. It gave rise to extensive discussion, during which there was a quaint comment to the effect that "at Harvard, by a long process of pushing and fighting for it. pediatrics is now recognized as one of the important branches, and the professor of pediatrics holds a chair in the faculty on an equality with any other member of the faculty and receives a salary also."

Another landmark was the presidential address of August Caillé in 1904 who said: "The American Pediatric Society should now be ready to assume broader obligations and to grapple with larger problems." His main theme was the improvement of conditions in public schools as they affect the health of children, a theme which was continued by his successor Jennings the following year, and amplified, and I quote: "It may not be the province of This Society to introduce reforms in school hygiene or other departments of sanitation... " The Society "may and should be ready, however, with its exceptional knowledge of child pathology, to unite with national education bodies, boards of health. and similar public organizations, in movements directed to the improvement in the physical development and well-being of the children of the nation. To this end a standing committee could be appointed with power to represent the Society, in national conferences and international congresses...."

He continued: "Until The American Pediatric Society thus gives its aid to such problems of national development, it will have but partially fulfilled its duty to scientific medicine, and the welfare of the children of the nation." Probably as a sequel to Jennings" presidential address a "Committee on the Welfare of Children" was set up at the executive session.

"The Position and Work of The American Pediatric Societl" Toward Public Questions" was the provocative title of the lead-off paper by Thomas Rotch Morgan in 1909. In the course of a very long discussion, Dr. Samuel Adams, the perennial, hustling. busthing secretary, expressed the opinion, based on listening to the program over eighteen years, "... that this Society has never taken the stand it should have taken in the matter of public affairs... We should now, even at this late date (in 1909), after twenty-one years of existence, and having reached our majority, assume the position to which we are entitled, that of a body competent to speak with authority on all questions of public interest in regard to the health and development of the child." With this view there was wide agreement in discussion, but it was not unanimous. The alternate view was stated by Abt: "It seems 
to me that it is our mission to stimulate and encourage scientific work to the very highest degree. It should be farthest from our purpose to become entangled in political or legislative questions." Emmett Holt, Sr., concurred, saying "I believe We can do our best work along the lines of research." Rotch disagreed strongly, emphasizing the duty of the medical profession to give the public the benefit of its knowledge.

Two very different concepts of the mission of The American Pediatric Society were thus clearly drawn in 1909 and have erupted again and again in its history, notably in 1929, when Henry Shaw of Albany concluded his presidential address by saying: "We are living in the daw'n of a new era in the practice of medicine. Let us awake to the magnificent opportunities for service that are opening on all sides."

Social action was uppermost in the minds of a group of pediatricians from the Pediatric Section of The American Medical Association who, between 1930 and 1932, organized The American Academy of Pediatrics. Some of those who joined were also members of The American Pediatric Society. They briefly considered trying to activate The American Pediatric Society but unanimously decided against it. Thus the mission of The American Academy of Pediatrics was from the start action oriented and has so remained. One gains the impression that the Academy was really founded by the dissident, action-oriented minorities of the other two pediatric groups-out of sheer frustration.

Leaving for a few moments the issue of social action, I would like to look at two characteristics of the Society which have changed remarkedly in the near century of its existence. Membership in the beginning was limited to 100: The members all knew each other, with the resulting spirit of good fellowship we have heard about. Even when I first attended a Society meeting thirtyfive years ago, the then 120 members were all acquainted with each other, and the younger visitors like me at least knew of all of the members. In that time there were relatively few pediatric training programs: pediatric interns and residents usually moved every year, so that if you did not actually know the chiefs from elsewhere, you knew of them through your fellow house officers. A kind of club atmosphere did indeed prevail.

Add to that the lack of subspecialization in pediatrics in earlier days, so that all sessions were plenary sessions. Subspecialization was in its infancy. It was really Edwards Park at the Harriet Lane who crystallized the idea in the mid-1930's, setting up the Special Clinics under the leadership of Helen Taussig. Leo Kanner, Lawson Wilkins, and others. But, really, all pediatricians were expected in those days to know everything about everything in pediatrics, or at least to know enough to be interested in every facet of pediatrics. Nowadays the subspecialty groups are so strong that most are in fact represented by special societies, often linking them to internists, cardiologists, psychiatrists, etc. with similar special interests; or even by special pediatric societies, such as The American Society for Pediatric Nephrology. Dr. Chester Edelmann, in a recent letter to Dr. Battaglia, questions the most appropriate and advantageous relationship between the general pediatric societies and the subspecialty societies. The plenary sessions of both the APS and the SPR have been criticized in recent years: either the communications are too specialized and appeal only to the connaisseurs; or they are pitched to be intelligible to all, but then they tend to lose punch.

Thus increasing membership, greater numbers of pediatric training centers, less mobility among house officers, and everburgeoning specialization have lysed the bonds between us. Little remains of the old "club atmosphere," and, anyhow, clubs are somewhat in eclipse these days.

What to do?

As President of the Society for Pediatric Research last year, Dr. Scriver organized a symposium entitled "Voyages to Discovery"-scholarly overviews of various avenues of research, which was immensely successful.

For the senior society I propose to you that it is appropriate for us to consider at our meeting some of the larger issues which bedevil our country and the world. As professors of pediatrics and senior practitioners in our communities, we are every day confronted and preoccupied with issues which we poorly understand, which we are timid about discussing with our students because we often have even less expertise than they, and about which we, as single individuals, can do nothing. And yet these are issues which grip our children and which vitally affect the future of our nation.

Consider, for a moment, our "culture of violence." Tens of thousands of our young people perish every year by motor vehicle accidents, murder, child abuse, and suicide. "Surely," to quote Ann Somers, "in this situation, the search for the causes and cures of violence merits the same degree of moral and intellectual commitment on the part of the health professions as we are currently devoting to the war on cancer; or once did to the war on tuberculosis."

To think about violence is to think about television, which indoctrinates our children in the "culture of violence." What should and could we as professors of pediatrics be doing about it?

Biomedical ethics is an area where most physicians are ill at ease, and yet who in the world today confronts more pressing ethical issues than the neonatologist? But he was not trained as an ethicist. Where else should he turn for help if not to his own professional peers?

Changing patterns of family life affect even the most dedicated of laboratory investigators when he leaves the lab bench to round with his house officers, or to return home in the evening.

The many interfaces between the child and the law are peculiarly difficult and perplexing to pediatricians in their role of child advocates. The members of the legal profession interested in child and family law are subspecialists also. Should we not cooperate and work jointly?

Government policies as they affect children, teaching, research are bewildering. Should we have a national policy for children? Maybe a Secretary for Children, as proposed by Dr. Lee Salk in a recent letter to The New York Times?

In the thought that it is timely for our Society to delve into these great issues, we have invited several special speakers to address The Society today.

Together, as members of The American Pediatric Society, we can hopefully gain insights which as individuals, as pediatricians, as specialists, we could not do so well. In short, we can acquire wisdom. The catch is, my friends, if you look up wisdom in the dictionary, you find not one but two definitions: (l) scholarly knowledge or learning and (2) knowledge of what is true or right coupled with just judgment as to action. As we listen to these presentations today, shall we consider them primarily for the edification of our members and guests, designed to broaden our horizons and give us new common interests? Should we put special individuals or committees or task forces to work preparing "judgments as to action" and then encourage other groups, such as The American Academy of Pediatrics, maybe the Ambulatory Pediatric Association, to carry out the action? Or should The American Pediatric Society, in some areas at least, get into the action itself?

That The American Pediatric Society will decide to become active in some well chosen area or areas is my own personal hope. American society as a whole is and always has been basically antichild oriented. The large sums of money we as a nation spend on alcoholic beverages contrasted with the small amounts on public education confirm our priorities. A rising suicide rate among our own children and adolescents attests to their loneliness and failure to appreciate their own worth. More children in our country live in poverty compared to the number of elderly, although the elderly would have us think otherwise and are naturally able to be more vocal. Repeatedly we hear from children in shelters and jails; from teenagers in high schools; from adolescents in colleges: "nobody cares"- how often have we all heard that?

Washington is said to be teaming with do-gooders interested in children. But frankly, and quite immodestly, I ask you-where can you find a group of people as interested in children, with as much knowledge about them, with such potentially helpful contacts in the community and the government as are assembled right 
here and now in this room? And shouldn't we be putting our wisdom and our talents at the service of children at a time when our country needs them so desperately? We would not only be serving our country, but creating within The American Pediatric Society new bonds to replace the old eroded ones.

Were the membership to agree that it would like to enter into an activist phase, a few practical considerations should be looked at. First, the goals as stated in the original constitution, were amended and broadened in 1950. Article II now states: "The objects of this Society shall be to bring together men and women for the advancement of the study of children and their diseases, for the prevention of illness and the promotion of health in childhood, for the promotion of pediatric education and research, and to honor those who, by their contributions to pediatrics, have aided in its advancement." This broad statement would not, it seems to me, limit any reasonable activity on behalf of children.

Next, the office of the President. The candidates for President, I hate to tell you, are usually chosen by the nominating committee from a list, prepared by the Secretary, of those members soon to become Emeritus. (The candidate for President this coming year, I hasten to add, is an exception to the custom!) As a way of honoring senior members of the Society this is fine, but if fresh, dynamic, imaginative policy and reasonable innovations are sought, some other criteria should be added or substituted. Also, the President serves for one year only, usually with no warning or preparation, then disappears. Worse than that, from the spring when he or she is elected, until the following February, there is no meeting of Council and officers. Hence the proposal now before the membership that the Vice-President in future automatically become President and then stay on a third year on the Council, as is done in some other societies to assure time to develop and implement ideas.

Before I turn the podium over to our Vice-President, Dr. Conrad Riley, who will chair this morning's experimental Special Plenary Session, I would like to add two postscripts. First, my brief historial review of The American Pediatric Society was designed to emphasize what $I$ wanted to emphasize (probably all historians do this, it's so much more fun) but in the interest of completeness one should point out one more interest of the Society which appeared in the early 1950's and culminated in the awarding of the first Howland medal in 1959. Honoring these members whose life exemplifies the ideals of our Society is, I believe eminently fitting, and it has in fact served as a strong unifying force among us. It has always been above and beyond controversy.

Some of you noticed that no title was announced for this address. I shall now give you the title: "Should The American Pediatric Society Broaden the Scope of its Interest to Include Ethical, Behavioral and Social Problems as They Affect Children and Should It Become In Part An Action-oriented Society?" 